\title{
Sn-Aided Joining of Cast Aluminum and Steel Through a Compound Casting Process
}

\author{
AINA OPSAL BAKKE, ARNE NORDMARK, LARS ARNBERG, and YANJUN LI
}

Obtaining a strong bond between aluminum and steel is challenging due to poor wettability between aluminum melt and steel and brittle intermetallic phases forming in the interface. In this research, a novel coating method, namely hot dipping of $\mathrm{Sn}$, has been developed to treat the steel insert surfaces. Results show that without preheating the mold or Sn-coated insert, a thin, crack-free, and continuous metallurgical bonding layer was achieved in the A356 aluminum/ steel compound castings. Intermetallic structures forming in the interface have been characterized in detail. The Sn-coating layer completely melted and mixed with the liquid aluminum during the casting process. The reaction layer at the aluminum/steel interface is composed of ternary Al-Fe-Si particles and a thin layer of binary $\mathrm{Al}_{5} \mathrm{Fe}_{2}$ phase with thickness less than $1 \mu \mathrm{m}$. A small fraction of dispersed Sn-rich particles was observed distributing in the reaction layer and adjacent to eutectic Si particles in the A356 alloy. A sessile drop wetting test showed that Sn-coated steel substrates can be well wetted by aluminum melt. The improved wettability between A356 alloy melt and steel was attributed to the penetration and breaking of the aluminum oxide layer at the surface of the aluminum droplets by liquid $\mathrm{Sn}$.

Graphic Abstract
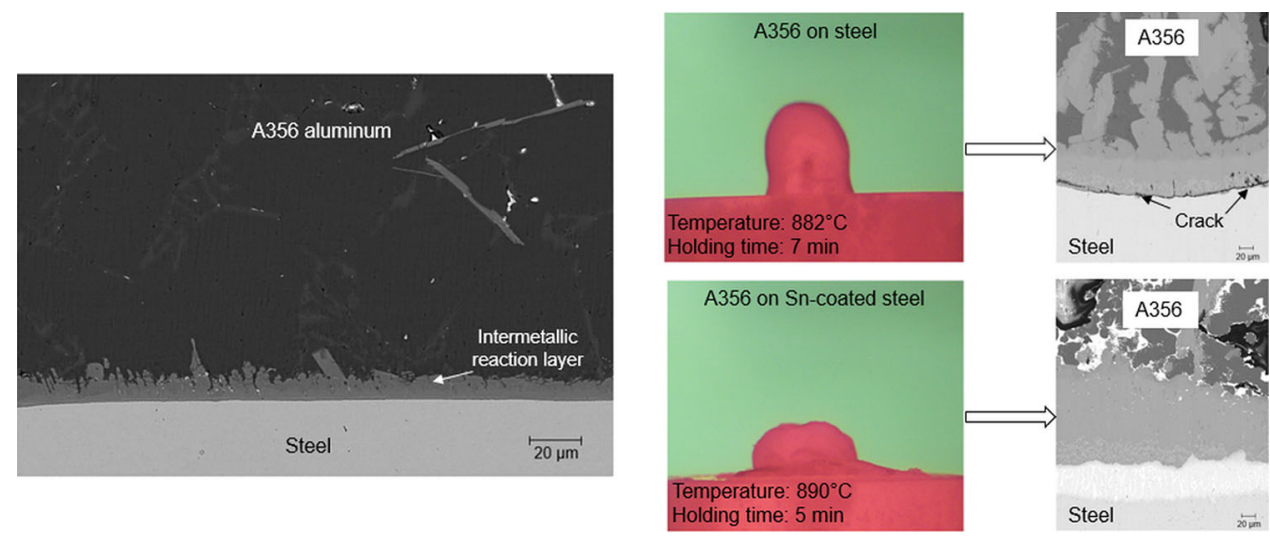

https://doi.org/10.1007/s11663-021-02329-w

(C) The Author(s) 2021

AINA OPSAL BAKKE, LARS ARNBERG, and YANJUN LI are with the Norwegian University of Science and Technology, Alfred Getz' vei 2, 7034 Trondheim, Norway. Contact e-mail: yanjun.li@ntnu.no ARNE NORDMARK is with the SINTEF Industry, Richard Birkelands vei 2B, 7034 Trondheim, Norway.

Manuscript submitted April 22, 2021; accepted September 10, 2021.

Article published online November 4, 2021.

\section{INTRODUCTION}

JOINING aluminum components and steel components is often necessary for some engineering applications. A combination of the light weight of aluminum with the high strength of steel can produce a compound component with both these properties. ${ }^{[1]}$ This is especially interesting for the automotive industry. ${ }^{[2]}$ However, due to differences in thermal and mechanical properties of aluminum and steel, it is difficult to achieve high-strength joints by conventional joining methods. ${ }^{[3]}$ 
In addition, several joining processes, such as friction stir welding, laser welding, and cold roll bonding, require specific geometries of the working pieces and long process times, making them less practical for mass production on an industrial scale, especially for complex-shaped components. ${ }^{[4-7]}$

Compound casting is a joining process where the goal is to achieve a diffusion zone between the two materials, so that a metallurgical bond will form. ${ }^{[8]}$ In the process, a material in liquid state is cast onto a second material in solid state. ${ }^{[9]}$ Compound casting has the advantage of less geometrical restrictions where more complex shapes can be easily produced. In addition, it has few process steps, which makes it ideal for low-cost and high production rate. ${ }^{[10,11]}$ Also, the metallurgical bonding between the two materials has a large potential to give a high-strength joint. However, to obtain high-strength compound castings, it is important to control the type of brittle intermetallic phases forming at the interface and reducing the thickness of the reaction layer. ${ }^{[12]}$

To achieve a metallurgical bond, good wettability between the steel insert and the liquid aluminum is necessary. On both the liquid aluminum and solid steel surfaces, the thermodynamically stable oxide layers will act as wetting barriers and can, thus, prevent formation of a metallurgical bond. ${ }^{[13,14]}$ As the surface oxides spontaneously form, removal or reduction of the layer, as well as preventing a new layer from forming, is needed to achieve good bonding. Zn coating by galvanization has been proposed as a promising method to protect the steel surface, as $\mathrm{Zn}$ has a relatively low melting temperature of $420{ }^{\circ} \mathrm{C}^{[15]}$ and can, therefore, melt during the casting process. Jiang et al. showed that a continuous metallurgical bond could be achieved using hot-dip galvanized steel inserts in a compound casting process with aluminum ZL114A (Al-6.75 pct Si-0.63 pct Mg). ${ }^{[16]}$ Prior to casting, the mold was preheated to $300{ }^{\circ} \mathrm{C}$, while the inserts were placed directly in the mold after hot-dip galvanizing at $450{ }^{\circ} \mathrm{C}$. In the compound casting, the reaction layer mainly consisted of ternary $\tau_{6}-\mathrm{Al}_{4.5} \mathrm{FeSi}$ (also known as $\beta$-phase) particles, which have a platelet structure and are known for their brittle and stress-inducing characteristics. ${ }^{[17]}$ Shin et al. also investigated the effect of $\mathrm{Zn}$ coating, both through galvanizing and galvannealing. ${ }^{[18]}$ They achieved a thinner reaction layer of 10 to $40 \mu \mathrm{m}$ in the galvanized castings by using a low preheating temperature of $190{ }^{\circ} \mathrm{C}$ for the mold and inserts, while in the galvannealed castings, with similar preheating temperature, the oxide layer was too thick to achieve any metallurgical bonding. Despite the thin and more uniform reaction layer, cracks were observed in the layer, which Shin et al. attributed to pre-existing oxides on the steel surface and differences in thermal expansion for the various intermetallic phases. In a previous study by the present authors, ${ }^{[19]}$ a low-pressure die casting method was used to produce compound castings between galvanized steel inserts and A356 aluminum, where the mold and steel inserts were preheated to $300{ }^{\circ} \mathrm{C}$ and $200{ }^{\circ} \mathrm{C}$, respectively. Successful metallurgical bonding was achieved using galvanized steel inserts. Although $\mathrm{Zn}$ coating has showed promising effects on protecting the steel surface and improving wettability, the preheating of the mold and steel inserts prior to compound casting is necessary, which makes the casting process more complex and causes significant growth of the intermetallic layer at the interface. ${ }^{[20]}$

Sn has a melting point of only $232{ }^{\circ} \mathrm{C}^{[15]}$ and a very low solubility in aluminum, with no intermetallic phases forming in the Al-Sn system. ${ }^{[21]}$ More importantly, Sn has been widely used as a coating layer for steel plates or foils. ${ }^{[22]}$ The low melting point will allow Sn-coating layer to melt during compound casting, potentially without preheating of the insert or mold prior to casting. This can also help prevent excessive growth of intermetallic phases in the reaction layer.

In this research, the effect of Sn-coating on the wetting behavior of A356 alloy melt and mild steel has been studied by a sessile drop wetting test and through compound casting. A significantly improved wettability is crucial in obtaining solid metallurgical bonding and thus a strong bimetallic component. The solidification structures of the interfacial reaction layers between aluminum and steel, in both compound castings and that formed between aluminum droplets and steel substrates via wetting experiments, have been characterized. The characterization of the interface will both describe the role of the coating layer as well as the properties of the joint. Based on this, the roles played by Sn have been discussed.

\section{MATERIALS AND METHODS}

\section{A. Casting Experiment}

S235JR mild steel pipes with a diameter of $20 \mathrm{~mm}$, thickness of $1.5 \mathrm{~mm}$, and length of $155 \mathrm{~mm}$ were used as the steel inserts for the compound casting. Chemical compositions of the mild steel, as well as the casting aluminum alloy A356, are given in Table I.

Before coating, the surface of the steel pipes was ground with 1200 grit paper, followed by cleaning in water and ethanol. They were then immersed in a $10 \mathrm{pct}$ $\mathrm{NH}_{4} \mathrm{Cl}$ solution at $75^{\circ} \mathrm{C}$ for 5 minutes. After removal from the salt solution, the pipes were left to air-dry. Commercially pure $\mathrm{Sn}$ was melted in an induction furnace at $400{ }^{\circ} \mathrm{C}$. To ensure that the steel pipes were completely dry after immersion in the salt solution, they were preheated to $100{ }^{\circ} \mathrm{C}$. Then the pipes were dipped in the melt for 5 minutes and then removed and cooled in air to room temperature.

The Sn-coated steel pipes were slightly ground with 1200 grit paper and cleaned in ethanol before they were placed in a sand mold, as shown in Figure 1. No preheating of the pipes or the mold was done. A

Table I. Chemical Composition [Wt Pct] of S235JR Mild Steel and Aluminum Alloy A356

\begin{tabular}{lccccccc}
\hline & $\mathrm{Mn}$ & $\mathrm{C}$ & $\mathrm{P}$ & $\mathrm{S}$ & $\mathrm{Fe}$ & & \\
\hline S235JR $^{[23]}$ & 1.4 & 0.17 & 0.045 & 0.045 & bal. & & \\
\hline & $\mathrm{Si}$ & $\mathrm{Mg}$ & $\mathrm{Ti}$ & $\mathrm{Fe}$ & $\mathrm{Sr}$ & Others & $\mathrm{Al}$ \\
\hline A356 & 7.0 & 0.41 & 0.11 & 0.082 & 0.013 & 0.016 & bal. \\
\hline
\end{tabular}




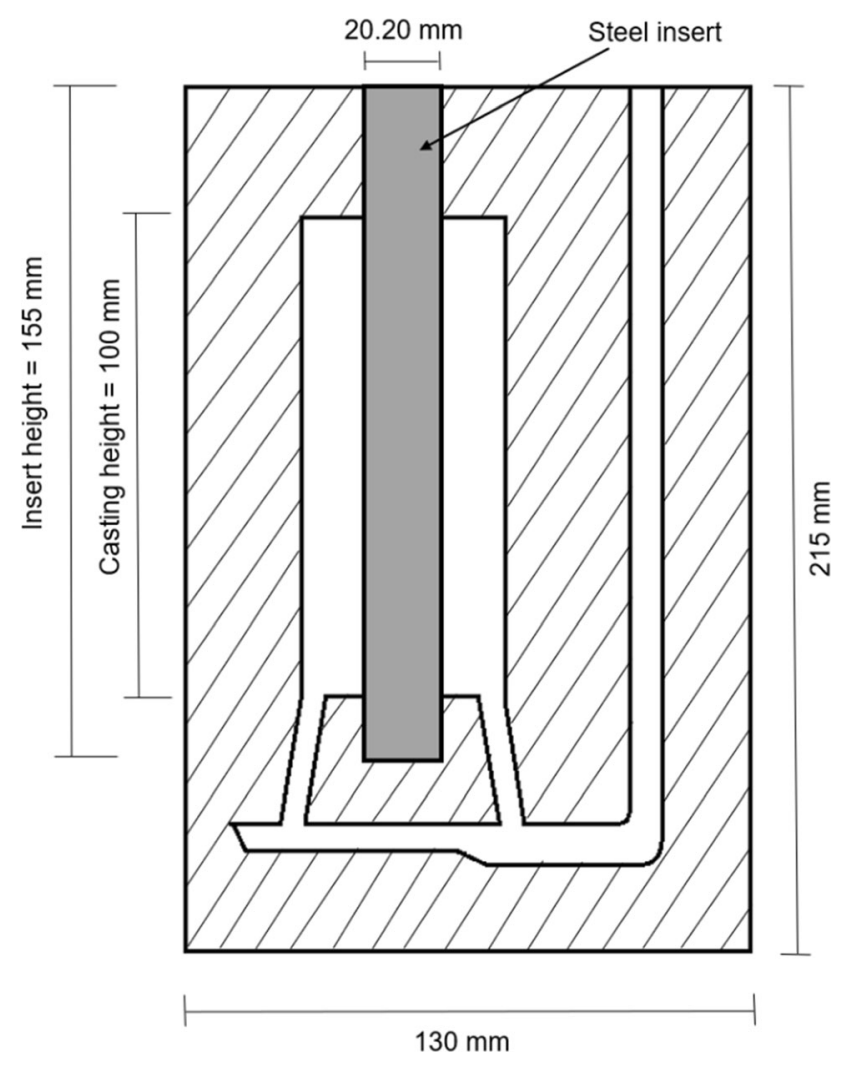

Fig. 1-Sketch of the sand mold used in the casting experiment.

commercial A356 cast aluminum alloy ingot was melted in an induction furnace to approximately $780{ }^{\circ} \mathrm{C}$. The liquid aluminum was poured into the mold at $730{ }^{\circ} \mathrm{C}$.

\section{B. Wetting Experiment}

A sessile drop wetting test was carried out in a wetting furnace consisting of a low-pressure chamber connected to an oil-filled heating system. $10 \mathrm{~mm}$ diameter S235JR mild steel bars, with the same composition as given in Table I, were cut into 3-mm-thick samples. Half of the samples were coated by hot dipping in liquid Sn using the same process as for the steel pipes. Small sample pieces of A356 alloy were prepared by cutting and polishing down to a weight of $0.0300 \pm 0.0011$ g. Prior to the wetting tests, all steel samples, coated and uncoated, were slightly ground with 800 grit paper. The steel samples and A356 pieces were then cleaned in a beaker with acetone in an ultrasonic bath for 5 minutes.

A piece of A356 alloy sample was placed on top of a steel substrate, which was then put in a graphite sample holder. To avoid any reaction between the steel substrate and the sample holder, an alumina substrate was placed between them. After the sample holder was led into the heating chamber, the vacuum pump was turned on. Once the pressure reached below $1 \times 10^{-3} \mathrm{~Pa}$, the heating was turned on. To break up the thick aluminum oxide layer at the surface of the aluminum sample, a testing temperature of $890{ }^{\circ} \mathrm{C}$ was used. It should be mentioned that at this temperature and vacuum

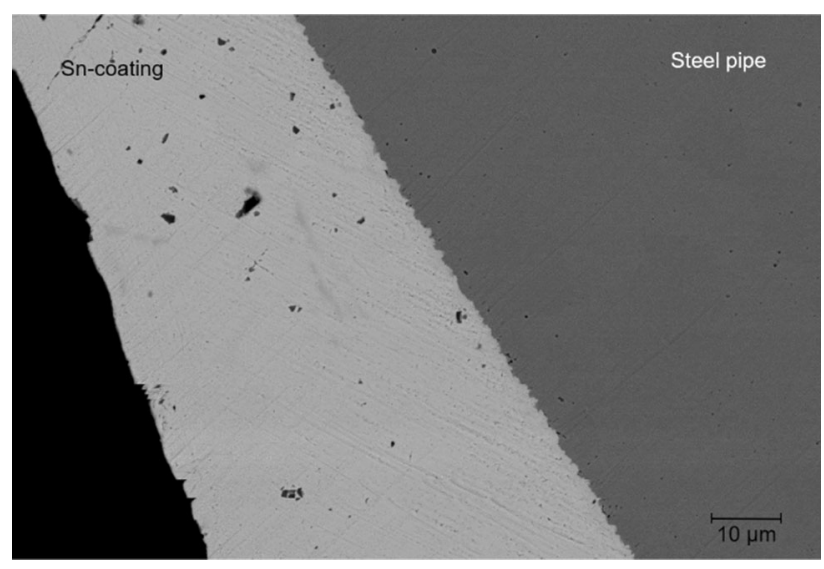

Fig. 2-Backscattered electron image of the Sn-coating prior to casting.

condition, it is impossible to evaporate the aluminum oxide layer at the droplet surface. ${ }^{[24]}$ Heating was conducted in two steps. First, a heating rate of approximately $140{ }^{\circ} \mathrm{C} / \mathrm{min}$ was used to reach $750{ }^{\circ} \mathrm{C}$, followed by further heating to $890{ }^{\circ} \mathrm{C}$ with a heating rate of $30{ }^{\circ} \mathrm{C} / \mathrm{min}$. During the experiment, images were taken with a frequency of one picture per second. After a total time of 15 minutes, the heating was turned off and the sample was left to solidify in the chamber before being removed.

\section{Sample Characterization}

After casting, the compound castings were cut in the transverse direction, and samples of approximately $1 \mathrm{~cm}$ thickness were obtained for metallographic study. The wetting test samples were mounted in epoxy and then cut perpendicular to the substrate surface so that the reaction layer between the A356 droplet and steel substrate could be further investigated. All samples were ground up to 4000 grits, then polished with 3 and 1 $\mu \mathrm{m}$ polishing suspensions. The cast samples were additionally polished using a Buehler Vibramet 2 vibratory polisher for a minimum of 10 hours. A Zeiss Supra 55VP Low Vacuum Field Emission Scanning Electron Microscope (LVFESEM) and a Zeiss Ultra 55 Field Emission Scanning Electron Microscope (FESEM) were used to study the reaction layers in the A356-steel interface in the various samples. Intermetallic phases in the reaction layers were analyzed through Energy Dispersive Spectroscopy (EDS) and a JEOL JXA-8500F Electron Probe Micro Analyzer (EPMA).

\section{RESULTS}

\section{A. Interfacial Reaction Layer in the Compound Castings}

Figure 2 shows a backscattered electron (BSE) image of the Sn-coating layer on a steel pipe prior to casting. From the figure it can be seen that the coating layer has good bonding with the steel and no defects can be observed in the steel/Sn interface. Thickness of the coating layer varies between approximately 40 to $60 \mu \mathrm{m}$. 


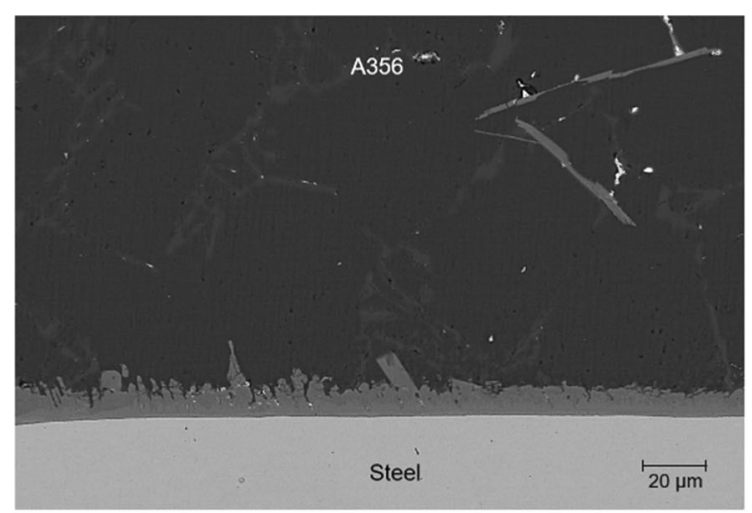

(a)

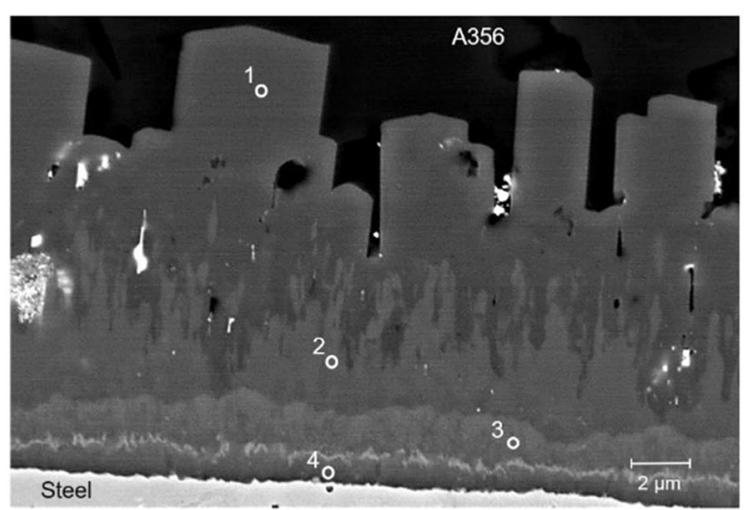

(b)

Fig. 3-BSE images of the reaction layer formed in the aluminum/steel interface. (a) Lower magnification image showing the reaction layer. (b) Higher magnified image showing the structure of the reaction layer.

Table II. Compositions of the Phases Formed in the Reaction Layer of the Compound Casting, Detected Through EDS

\begin{tabular}{lcrrl}
\hline \multirow{2}{*}{ Area } & \multicolumn{3}{c}{ Composition [At. Pct] } & \multirow{2}{*}{ Possible Phase } \\
\cline { 2 - 4 } & $\mathrm{Al}$ & $\mathrm{Fe}$ & $\mathrm{Si}$ & \\
\hline 1 & 67.33 & 14.89 & 17.78 & $\beta-\mathrm{Al}_{4.5} \mathrm{FeSi}$ \\
2 & 68.13 & 18.09 & 13.78 & $\alpha-\mathrm{Al}_{7.4} \mathrm{Fe}_{2} \mathrm{Si}$ \\
3 & 63.45 & 22.17 & 14.37 & $\tau_{11}-\mathrm{Al}_{4} \mathrm{Fe}_{1.7} \mathrm{Si}$ \\
4 & 66.74 & 27.22 & 6.05 & $\eta-\mathrm{Al}_{5} \mathrm{Fe}_{2}$ \\
\hline
\end{tabular}

A BSE image of the reaction layer formed in the aluminum/steel interface of the compound castings is shown in Figure 3(a). Continuous metallurgical bonding has formed throughout the interface. The reaction layer has a somewhat irregular shape, as a result of the growth of coarse intermetallic particles into the cast aluminum. An average thickness of the reaction layer is measured to approximately $12 \mu \mathrm{m}$. The original Sn-coating layer cannot be seen in the compound casting. Instead, small white areas, which through EDS are determined as Sn-rich particles, can be observed adjacent to the eutectic silicon particles in the cast aluminum, showing that the coating layer has completely melted and mixed with the aluminum melt during casting. Figure 3(b) shows a higher magnification BSE image of the reaction layer. The contrast variations in the reaction layer suggest the formation of different types of intermetallic phases. EDS analyses were used to investigate the phases formed. Detected compositions are shown in Table II.

The dominant phase (area 1), which has a coarse platelet morphology toward the cast aluminum, was determined as the ternary eutectic phase $\beta-\mathrm{Al}_{4.5} \mathrm{FeSi}$. With decreasing distance to the steel surface, the intermetallic particles show an increase in contrast. Beneath the $\beta-\mathrm{Al}_{4.5} \mathrm{FeSi}$ layer, the layer of dendrite-like intermetallic particles (area 2 in Figure 3(b)) are determined as $\alpha-\mathrm{Al}_{7.4} \mathrm{Fe}_{2} \mathrm{Si}$, which has higher Fe content and lower Si content than the $\beta$-phase. The intermetallic layer of area 3 has similar Si concentration as area 2, but a higher concentration of $\mathrm{Fe}$, which is consistent with the difference in contrast of the two layers. It suggests that the two layers are composed of two different phases. The lower $\mathrm{Al} / \mathrm{Fe}$ ratio in area 3 coincides with $\tau_{11}-\mathrm{Al}_{4} \mathrm{Fe}_{1.7} \mathrm{Si}$. At the steel surface, a thin layer of intermetallic phase with a thickness of approximately $0.8 \mu \mathrm{m}$ and a darker contrast can be observed (area 4). Despite the detection of some silicon in this area, the intermetallic particles in the layer are likely binary $\eta-\mathrm{Al}_{5} \mathrm{Fe}_{2}$, as this binary phase is known to form rapidly, with a parabolic growth rate, in the interface between molten aluminum and solid steel. ${ }^{[25]}$ Between the $\tau_{11}-\mathrm{Al}_{4} \mathrm{Fe}_{1.7} \mathrm{Si}$ and $\eta-\mathrm{Al}_{5} \mathrm{Fe}_{2}$, a narrow layer with bright contrast can be seen. This contrast difference suggests that the layer contains higher amounts of heavier elements, such as iron and tin. However, this was not detected through the EDS analysis. Instead, similar compositions as detected in area 3 were found. Although these heavier elements were not detected through the EDS analysis, it is likely that the narrow bright layer is made of Sn-rich phases that have remained between the $\tau_{11}-\mathrm{Al}_{4} \mathrm{Fe}_{1.7} \mathrm{Si}$ and $\eta-\mathrm{Al}_{5} \mathrm{Fe}_{2}$ phases after solidification. To determine this, further studies must be conducted.

An element mapping of the various phases in the reaction layer was conducted by electron probe micro analysis (EPMA) and the results are shown in Figure 4. Based on the distribution of $\mathrm{Al}, \mathrm{Fe}$ and $\mathrm{Si}$, it can be seen that all three elements are detected throughout the reaction layer. The $\mathrm{Fe}$ concentration decreases from the steel pipe toward the cast aluminum, while the $\mathrm{Si}$ concentration increases in the same direction. This is in agreement with the EDS analysis in Table II, where the intermetallic phases closer to the steel surface contain higher Fe content. In the Si mapping image, the white areas seen in the A356 side are due to eutectic silicon forming in the A356 alloy. In the Sn distribution map, it can be seen that a large number of finely dispersed Sn-rich areas are distributed along the interface. 


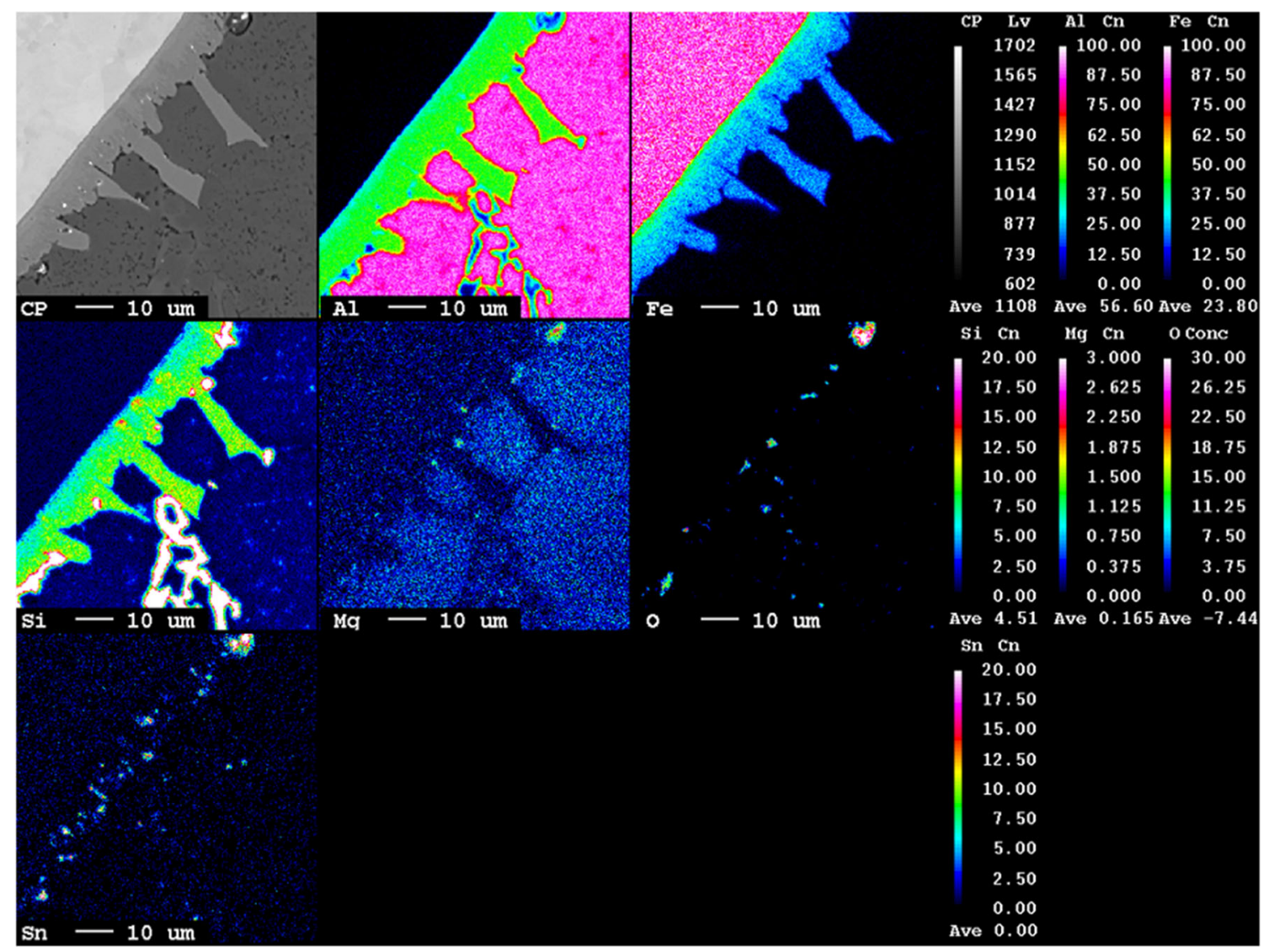

Fig. 4-Element mapping of the various phases at the aluminum/steel interface.

Interestingly, in the $\mathrm{Mg}$ map the $\mathrm{Mg}$-rich areas are overlapping with $\mathrm{Sn}$-rich areas. In addition to the $\mathrm{Mg}, \mathrm{O}$ can also be observed in some of the Sn-rich areas. These results suggest that $\mathrm{Sn}$ and $\mathrm{Mg}-\mathrm{Sn}$-rich oxide particles have formed in the interface region. The $\mathrm{Sn}$ particles inside the reaction layer may explain the high contrast layer between area 3 and area 4 in Figure 3(b).

\section{B. Wetting Behavior of A356 Melt Against Steel Substrate}

Figure 5 shows images taken during the wetting experiment between aluminum A356 and an uncoated steel substrate. The initial shape of the A356 piece is shown in Figure 5(a). After heating to approximately $800{ }^{\circ} \mathrm{C}$, the A356 piece changes into a drum shape (Figure 5(b)), suggesting that the piece is molten inside. When further increasing the temperature to $870{ }^{\circ} \mathrm{C}$, the shape of the A356 piece becomes more circular. However, only a slight contact between the aluminum and steel substrate seems to occur, as seen in Figure 5(c). Finally, after heating to approximately $882^{\circ} \mathrm{C}$ and maintaining at this temperature for about 7 minutes, the solid A356 piece is completely melted (Figure 5(d)).
However, only limited spreading of the aluminum melt has occurred in the bottom of the droplet, while the top part remained in a circular shape. This is due to the surface oxide layer that constrains the liquid aluminum at the core of the droplet. It clearly indicates that the inert surface aluminum oxide layer strongly resists the wetting between aluminum melt and steel.

Wetting behavior between the A356 piece and the Sn-coated steel substrate is shown in Figure 6. The initial appearance of the coated substrate and A356 piece is shown in Figure 6(a), where the uneven substrate surface is due to the coating layer. During heating to approximately $800{ }^{\circ} \mathrm{C}$ (Figure 6(b)), the $\mathrm{Sn}$ layer has completely melted, and an uneven film of liquid $\mathrm{Sn}$ can be observed on the substrate surface. In addition, the A356 piece has started becoming slightly rounder, indicating that the core of the $\mathrm{A} 356$ piece has become molten. At $870^{\circ} \mathrm{C}$ (Figure $6(\mathrm{c})$ ), the top part of the A356 piece has obtained a circular shape. With further increase in temperature, it can be seen that the height of the A356 piece starts decreasing due to spreading of the aluminum droplet on the surface of the $\mathrm{Sn}$ melt, and the molten $\mathrm{Sn}$ is pushed away (Figures 6(d) and (e)). After holding at $890{ }^{\circ} \mathrm{C}$ for 


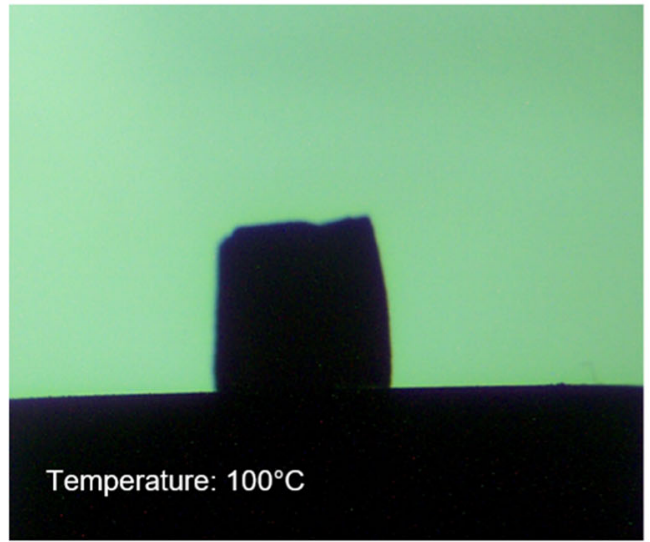

(a)

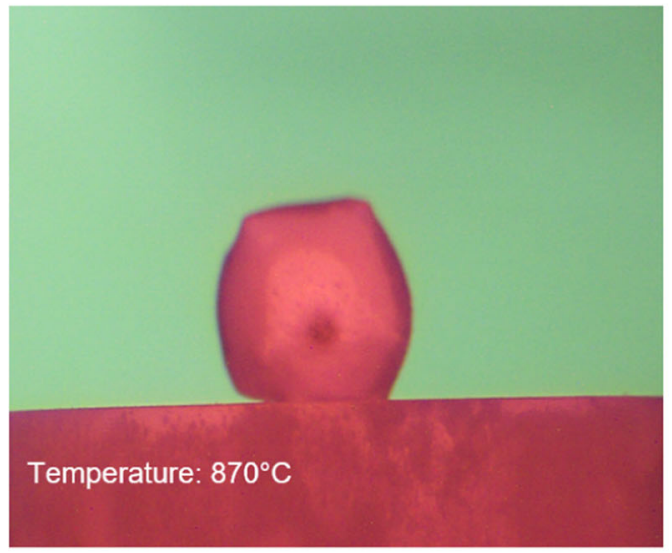

(c)

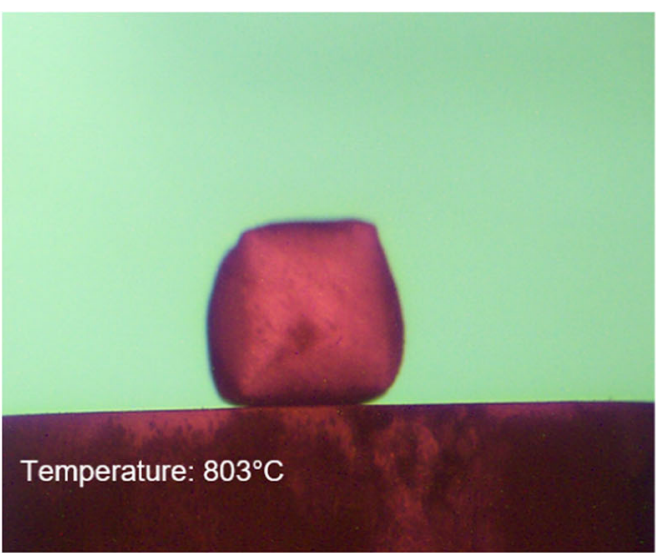

(b)

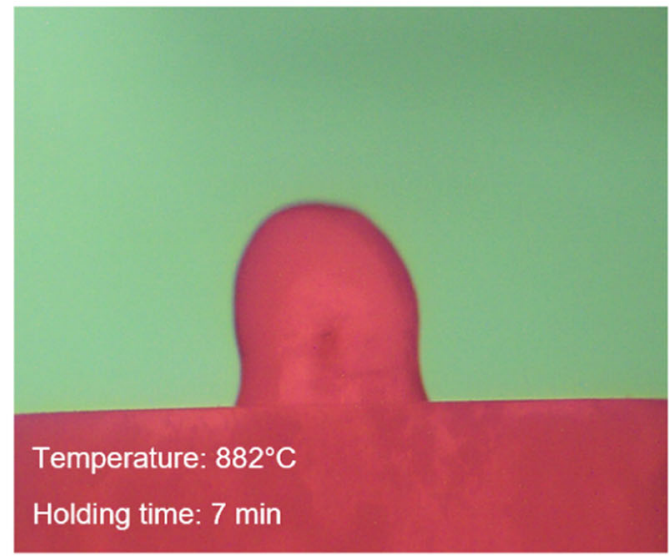

(d)

Fig. 5-The wetting behavior of A356 aluminum droplet to the steel substrate during the wetting experiment. (a) Initial shape of the A356 aluminum droplet at $100{ }^{\circ} \mathrm{C}$. (b) Wetting appearance at approximately $800{ }^{\circ} \mathrm{C}$. (c) Wetting appearance at approximately $870{ }^{\circ} \mathrm{C}$. $(d)$ Wetting appearance after remaining at approximately $880^{\circ} \mathrm{C}$ for $7 \mathrm{~min}$.

approximately 5 minutes, the A356 piece displays a further reduction in height and spreading on top of the Sn melt. Compared to the final wetting appearance observed in Figure 5(d), for the uncoated steel substrate, it is evident from Figure 6(f) that liquid aluminum has completely spread on the $\mathrm{Sn}$-coated steel substrate. This suggests that the Sn-coating has significantly improved the wettability between aluminum A356 and steel.

After the wetting experiment, the solidified droplets on the surface of the steel substrates were studied. Figure 7 shows BSE images of the aluminum/steel interfaces in the wetting experiment without surface coating (Figures 7(a) and (b)) and with Sn-coating (Figures 7(c) and (d)). It can be seen that reaction layers between the aluminum melt and the steel only formed in local regions for the substrate without surface coating. The fraction of the reaction layer is about 70 pct of the interface. Between these reaction regions, a large fraction of gaps can be observed. This indicates that the wetting between the aluminum droplet and uncoated steel surface is poor, which is believed to be a result of the aluminum oxide layer remaining in the interface. Such surface aluminum oxide layers surrounding aluminum droplets have been shown clearly in other wetting experiments. ${ }^{[24]}$ At the same time, multiple large plate-like Al-Fe particles have formed in the aluminum droplet, indicating that some steel has dissolved into the aluminum melt. A magnified image of the reaction layer enclosed by the black rectangle in Figure 7(a) is shown in Figure 7(b). As can be seen, a thick layer of intermetallic phases has formed at the interface. However, in the interface between the steel surface and the adjacent intermetallic phase, an almost continuous crack has formed.

In the Sn-coated sample, a continuous bond has formed between the A356 droplet and the steel substrate (Figure 7(c)). Compared to the compound castings shown in Figure 3, the reaction layer in the wetting sample is much thicker, which is due to the longer time and higher temperature of reaction between the liquid aluminum and the steel substrate. The network-shaped white areas in the droplet are determined as Sn-rich particles, indicating a sufficient mixing of liquid $\mathrm{Sn}$ with the aluminum droplet. This would suggest that the Sn-coating has helped to break the oxide layer at the interface. Figure 7(d) shows a higher magnification BSE image of the area in the black rectangle in Figure 7(c). In contrast to the uncoated steel surface, no cracks can be 


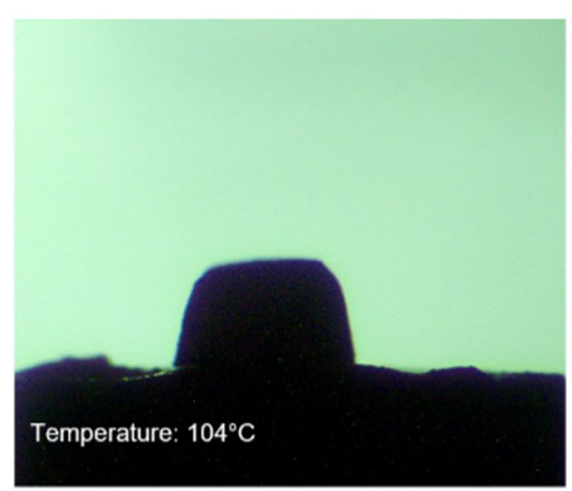

(a)

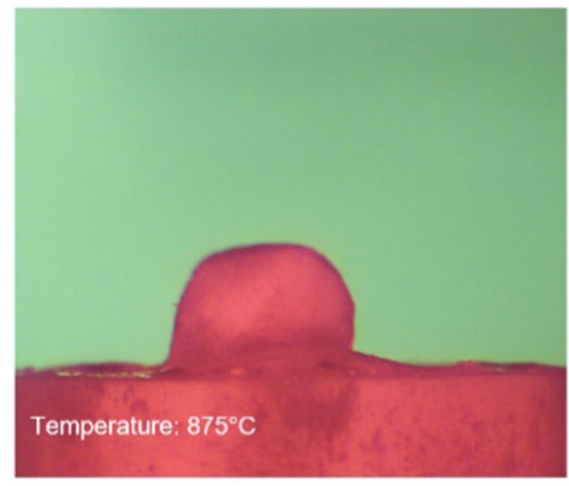

(d)

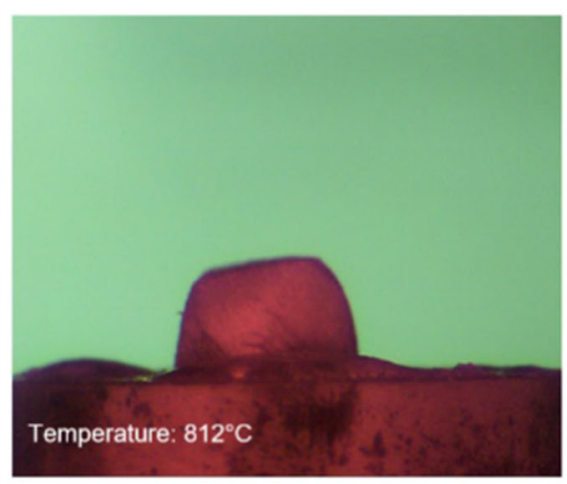

(b)

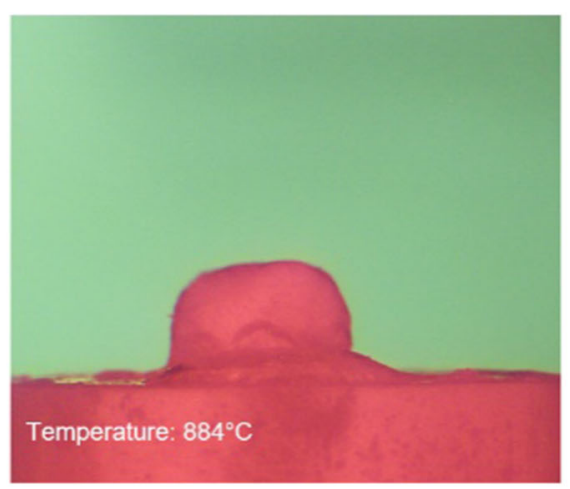

(e)

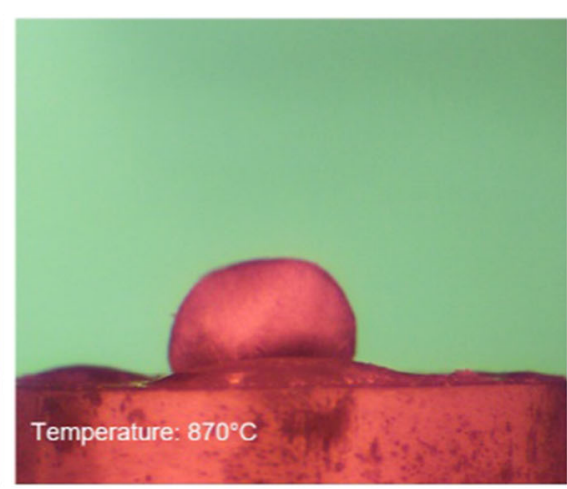

(c)

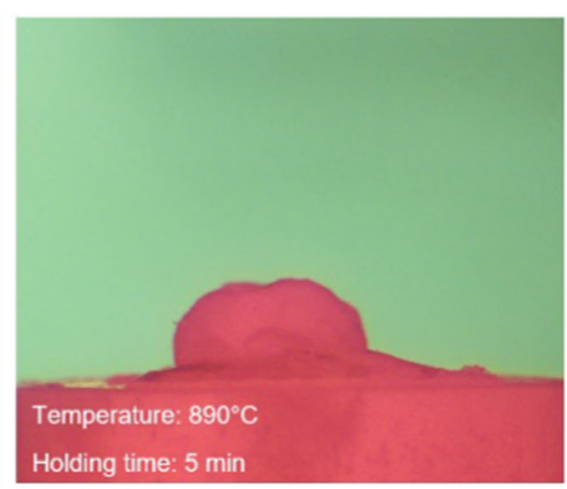

(f)

Fig. 6-The wetting behavior of A356 aluminum droplet to the Sn-coated steel substrate during the wetting experiment. (a) Initial shape of the A356 aluminum droplet at approximately $100{ }^{\circ} \mathrm{C}$. (b) Wetting appearance at approximately $810{ }^{\circ} \mathrm{C}$. (c) Wetting appearance at $870{ }^{\circ} \mathrm{C}$. $(d)$ Wetting appearance at $875^{\circ} \mathrm{C}$. (e) Wetting appearance at approximately $885^{\circ} \mathrm{C}$. (f) Wetting appearance after remaining at approximately $890{ }^{\circ} \mathrm{C}$ for $5 \mathrm{~min}$.

observed in the reaction layer. The interfaces, however, do have a similar appearance regarding intermetallic phases to that in Figure 7(b), with the exception of a layer of bright contrast (area 9 in Figure 7(d)) that has formed adjacent to the steel substrate in the Sn-coated sample. To determine the phases formed, EDS analyses were conducted. Detected compositions are shown in Table III.

From the compositions in Table III, it can be seen that similar phases have formed in the interfaces of both solidified wetting samples with and without Sn-coating of the steel substrate. However, some differences can be observed. The large, elongated particles observed both at the interface and in the A356 droplet appear to be the ternary $\alpha-\mathrm{Al}_{7.4} \mathrm{Fe}_{2} \mathrm{Si}$ phase in the uncoated sample (area 2 ), whereas the composition of the elongated particles in the Sn-coated sample coincides with the binary $\theta-\mathrm{Al}_{3} \mathrm{Fe}$ phase (area 5). This phase is slightly larger in the interface of the uncoated sample and, as seen in area 1 in Figure 7(b), an increase in $\mathrm{Fe}$ and a significant decrease in Si concentration are detected. Based on this change, it is likely that the center parts of the particles are composed of binary $\theta-\mathrm{Al}_{3} \mathrm{Fe}$ phase. This outer layer of the particles has formed by phase transformation from $\theta-\mathrm{Al}_{3} \mathrm{Fe}$ to $\alpha-\mathrm{Al}_{7.4} \mathrm{Fe}_{2} \mathrm{Si}^{[26]}$ The layer adjacent to the steel surface in the uncoated sample (area 3) and the dominating phase in the Sn-coated sample (area 6) are determined to be $\eta-\mathrm{Al}_{5} \mathrm{Fe}_{2}$. Within this phase, small grains of other phases have formed. Compositions of these smaller grains (areas 4 and 7) are close to the ternary $\tau_{11}-\mathrm{Al}_{4} \mathrm{Fe}_{1.7} \mathrm{Si}$ phase. Interestingly, this phase is only observed within the $\eta-\mathrm{Al}_{5} \mathrm{Fe}_{2}$ close to the steel surface, where such a high $\mathrm{Si}$ concentration would not be expected. In the Sn-coated sample, an additional intermetallic layer can be observed. This layer consists of elongated particles with high contrast (area 8) surrounded by a second phase with brighter contrast than the steel surface (area 9). From the composition in area 8 , the bright elongated particles appear to be $\mathrm{FeSn}_{2}$. The composition of the surrounding matrix suggests that it is an iron phase enriched with $\mathrm{Sn}$. This layer is thus supposed to be the incompletely melted reaction layer between $\mathrm{Sn}$ and steel forming during the coating process.

\section{DISCUSSION}

\section{A. Effect of Sn-Coating on Wettability}

In the wetting experiment, a clear difference in the wetting behavior of the A356 droplet at the steel substrate surface with and without Sn-coating have been observed. During heating, the height of the droplet 


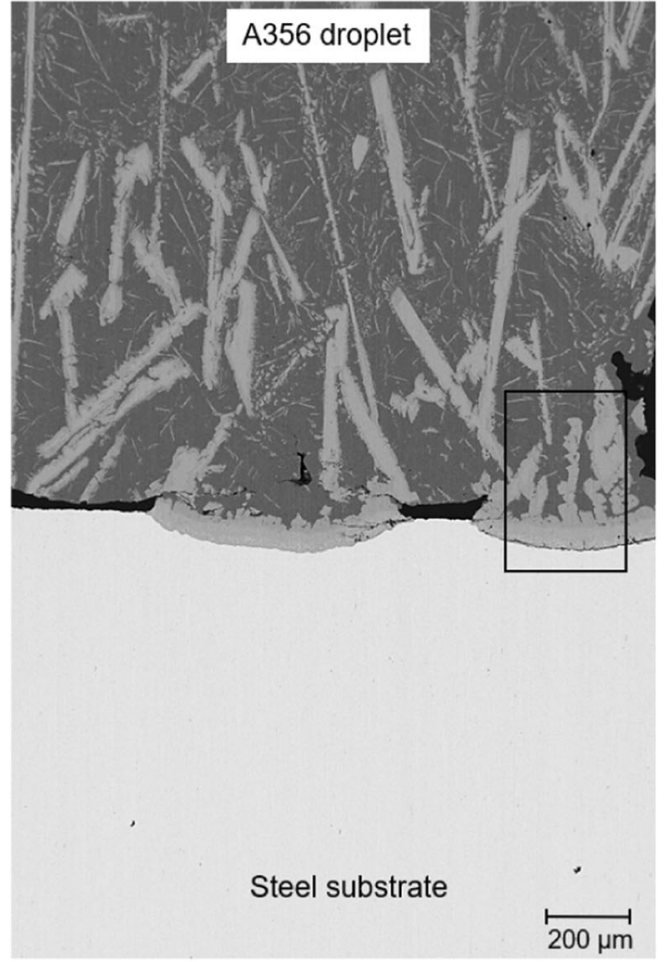

(a)

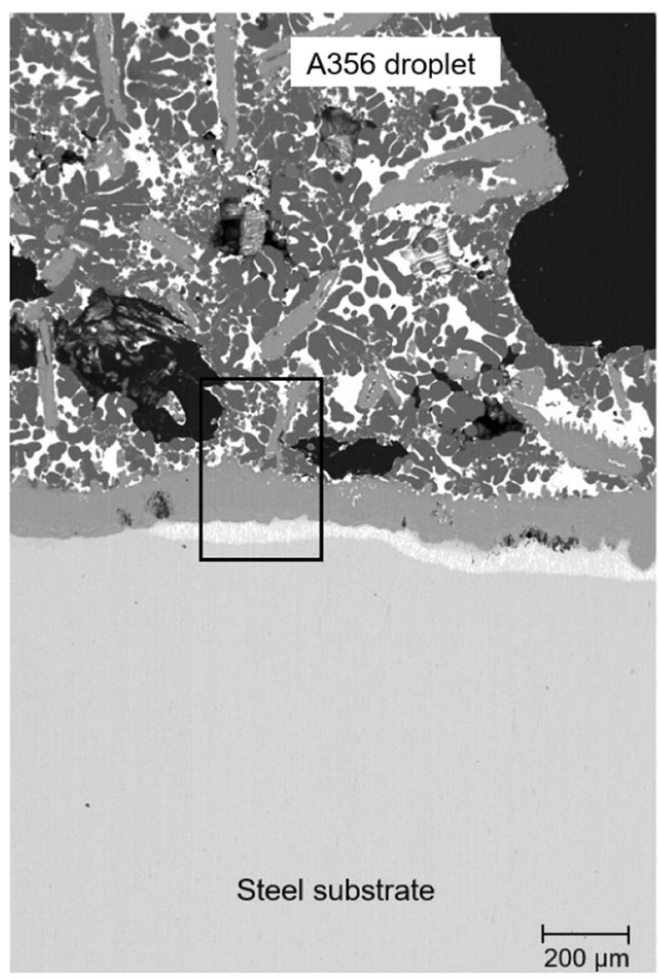

(c)

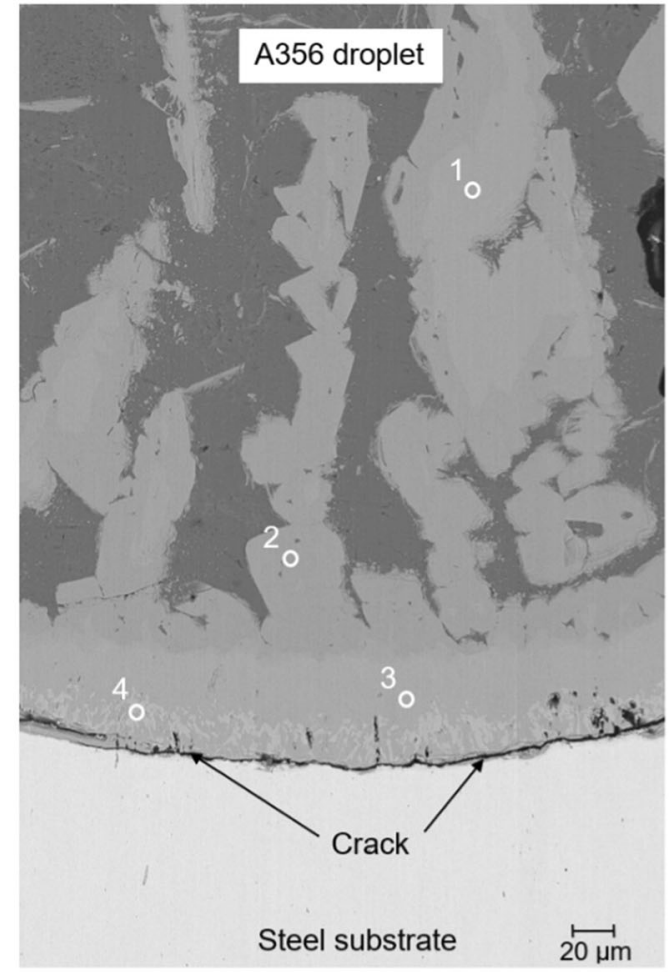

(b)

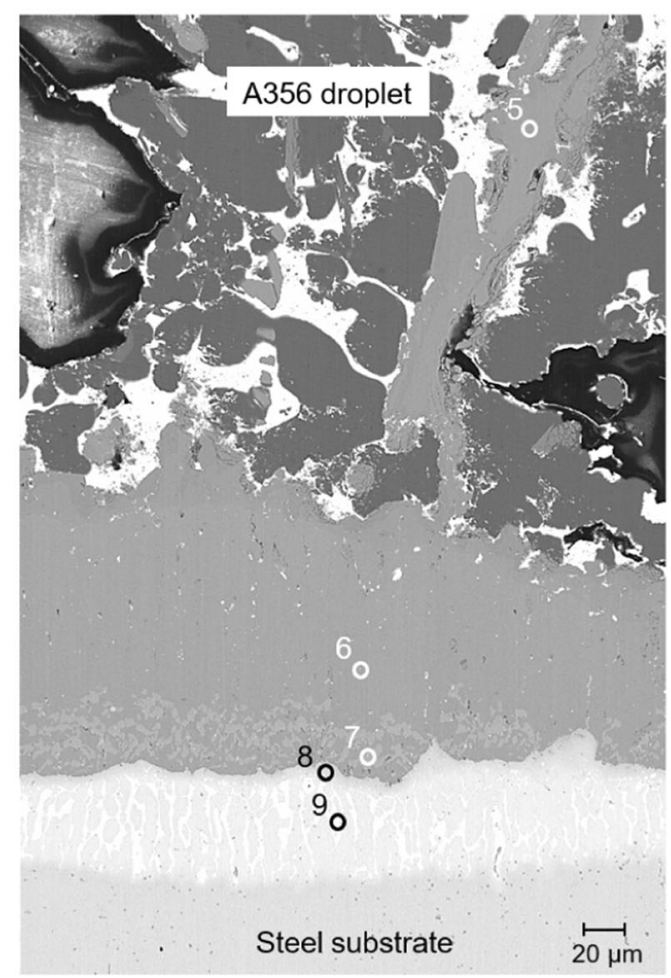

(d)

Fig. 7-BSE images of the aluminum/steel interfaces after the wetting experiment. $(a)$ and $(b)$ Uncoated steel substrate. $(c)$ and $(d)$ Sn-coated steel substrate.

on the Sn-coated surface decreases continuously with time and it does not achieve the same semispherical shape as the droplet on the uncoated substrate. This indicates that some reactions occur at the interface between the aluminum droplet and the liquid Sn layer on the steel. It is speculated that liquid Sn has destroyed 
Table III. Compositions Detected Through EDS from the Aluminum/Steel Interface in the Wetting Experiment Samples

\begin{tabular}{lrrrrl}
\hline \multirow{2}{*}{ Area } & \multicolumn{4}{c}{ Composition [At. Pct] } & \multirow{2}{*}{ Possible Phase } \\
\cline { 2 - 4 } & \multicolumn{1}{c}{$\mathrm{Al}$} & \multicolumn{1}{c}{$\mathrm{Si}$} & \multicolumn{1}{c}{$\mathrm{Fe}$} & $\mathrm{Sn}$ & \\
\hline 1 & 74.29 & 2.82 & 22.89 & - & $\theta-\mathrm{Al}_{3} \mathrm{Fe}$ \\
2 & 71.18 & 10.28 & 18.54 & - & $\alpha-\mathrm{Al}_{7.4} \mathrm{Fe}_{2} \mathrm{Si}$ \\
3 & 69.24 & 4.22 & 26.54 & - & $\eta-\mathrm{Al}_{5} \mathrm{Fe}_{2}$ \\
4 & 50.70 & 15.85 & 33.45 & - & $\tau_{11}-\mathrm{Al}_{4} \mathrm{Fe}_{1.7} \mathrm{Si}$ \\
5 & 73.08 & 4.06 & 22.86 & - & $\theta-\mathrm{Al}_{3} \mathrm{Fe}$ \\
6 & 69.07 & 4.62 & 26.31 & - & $\eta-\mathrm{Al}_{5} \mathrm{Fe}_{2}$ \\
7 & 50.12 & 15.84 & 34.04 & - & $\tau_{11}-\mathrm{Al}_{4} \mathrm{Fe}_{1.7} \mathrm{Si}$ \\
8 & 2.46 & - & 61.04 & 36.49 & $\mathrm{FeSn}_{2}$ \\
9 & 1.25 & 0.66 & 91.66 & 6.43 & $\mathrm{Sn}_{-2 n r i c h e d ~ F e}$ \\
\hline
\end{tabular}

the original aluminum oxide layer covering the aluminum droplet, making the spreading of the aluminum droplet easier. A previous wetting experiment at $1000{ }^{\circ} \mathrm{C}$ has shown that it took 750 minutes to break the oxide layer at the aluminum droplet surface by high vacuum. ${ }^{[27]}$ Thus, the temperature used in this experiment is not sufficient to remove the aluminum oxide layer completely. This can explain why the aluminum droplets did not show a normal droplet shape during the wetting test. In a wetting experiment by Lin et al., a contact angle of 30 deg was obtained between a $\mathrm{Sn}$ droplet and an Al substrate at $400^{\circ} \mathrm{C}$ despite a nanometer thick oxide layer being detected on the substrate surface. ${ }^{[28]}$ They suggested that this was due to cracks emerging in the oxide layer as a result of different thermal expansion coefficients of $\mathrm{Al}$ and $\mathrm{Al}_{2} \mathrm{O}_{3}$, through which liquid $\mathrm{Sn}$ can permeate. Once Sn the liquid Sn permeates these cracks, it can help further break up the oxide layer and thus ensure spreading of the liquid Al. This coincides with the more deflated appearance of the A356 droplet on the Sn-coated steel substrate during the wetting experiments in this work. A similar effect is suggested to occur during compound casting, where the melted Sn-layer at the steel surface could contribute to the breaking up of the aluminum oxide surface layer of the flowing aluminum melt, thus improving the wettability between the aluminum melt and steel.

After compound casting, only small Sn-rich particles could be detected in the reaction layer and in the cast aluminum. The low melting point of Sn causes the $\mathrm{Sn}$ to solidify last and thus solidify along the eutectic silicon. This distribution of $\mathrm{Sn}$ in the cast aluminum is wanted, as large Sn particles could potentially reduce mechanical properties of the overall component. ${ }^{[29]}$ Interestingly, some of the Sn-rich particles also have a high concentration of $\mathrm{Mg}$, which suggests that some $\mathrm{Sn}-\mathrm{Mg}$ intermetallic phases may have formed.

Despite being somewhat irregular, the reaction layer of the compound casting is measured to be approximately $12 \mu \mathrm{m}$ in average. Compared to other compound casting experiments with surface coatings such as $\mathrm{Zn}$ coating and aluminizing, where the reaction layer thicknesses were reported to be as high as $650 \mu \mathrm{m},{ }^{[30]}$ Sn-coating provides a significantly thinner reaction layer. The thickness reduction is due to the low melting point of Sn allowing casting to be conducted without preheating of the steel pipes or the mold. Thus, there will be less time for interdiffusion of $\mathrm{Al}$ and $\mathrm{Fe}$ atoms, and formation and growth of intermetallic phases. Furthermore, an avoidance of preheating of the steel insert and mold can significantly reduce the complexity and cost of compound casting, thus making it more efficient from an industrial point of view.

\section{B. Microstructure Formation in the Intermetallic Reaction Layer}

The intermetallic reaction layer in the compound castings can be seen growing toward the cast aluminum. When the aluminum melt comes in contact with the steel insert, the Sn-coating layer will melt and mix with the aluminum. Thus, the fresh liquid aluminum alloy can directly react with the steel surface. Once in contact, interdiffusion of $\mathrm{Al}$ and $\mathrm{Fe}$ atoms starts at the interface. Due to the high content of $\mathrm{Fe}$ in the local reaction region, it is natural that $\eta-\mathrm{Al}_{5} \mathrm{Fe}_{2}$ is the first intermetallic phase to form, as it is known to have a rapid growth rate. ${ }^{[3,31]}$ Interestingly, only a thin layer of the $\eta-\mathrm{Al}_{5} \mathrm{Fe}_{2}$ phase has formed and no $\theta-\mathrm{Al}_{3} \mathrm{Fe}$ was detected in the interface. This differs from the reaction layer observed by Shin et al., where no $\eta-\mathrm{Al}_{5} \mathrm{Fe}_{2}$ was detected but a relatively thick $\theta-\mathrm{Al}_{3} \mathrm{Fe}$ layer formed in the interface. ${ }^{[18]}$ The increased cooling rate due to no preheating in the current research might be the reason for the formation of thin $\eta-\mathrm{Al}_{5} \mathrm{Fe}_{2}$ layer, instead of a thick $\theta-\mathrm{Al}_{3} \mathrm{Fe}$ layer. Additionally, it is reported that $\alpha-\mathrm{Al}_{7.4} \mathrm{Fe}_{2} \mathrm{Si}$ could be formed through a peritectic reaction between liquid $\mathrm{Al}$ and $\theta-\mathrm{Al}_{3} \mathrm{Fe}$ phase. ${ }^{32]}$ Thus, it is possible that if $\theta-\mathrm{Al}_{3} \mathrm{Fe}$ phase formed initially, it further reacted with liquid $\mathrm{Al}$ to form $\alpha-\mathrm{Al}_{7.4} \mathrm{Fe}_{2} \mathrm{Si}$. $\tau_{11}-\mathrm{Al}_{4} \mathrm{Fe}_{1.7} \mathrm{Si}$ will then form adjacent to the $\alpha$-phase as the Si concentration increases. Another difference observed in the interface in the present research compared to similar compound castings with $\mathrm{Zn}$ coating, is the fraction and shape of the ternary $\beta-\mathrm{Al}_{4.5} \mathrm{FeSi}$ phase. This eutectic ternary phase is the last to form in the $\mathrm{Al} /$ steel interface in this work and has been reported to form both through a eutectic reaction and a peritectic reaction between the liquid $\mathrm{Al}$ and $\alpha-\mathrm{Al}_{7.4} \mathrm{Fe}_{2} \mathrm{Si}^{[33]}$ In the works of Jiang et al. ${ }^{[16,30]}$ and our previous work, ${ }^{[19]} \beta-\mathrm{Al}_{4.5} \mathrm{FeSi}$ is the main phase formed in the aluminum/steel reaction layer. The phase is found both as platelet-shaped grains growing from the steel surface toward the cast aluminum and as platelet particles in the bulk of the cast aluminum. In the present Sn-coating aided compound casting, the platelets of the $\beta$-phase are significantly shorter. Additionally, the fraction of $\beta$-phase in the reaction layer and in the cast aluminum adjacent to the reaction layer is much lower than mentioned in the previous works, as can be observed in the BSE micrographs in Figure 3. As the $\beta$ - $\mathrm{Al}_{4.5} \mathrm{FeSi}$ phase is known as a brittle and stress-in- 
ducing phase due to its platelet shape, ${ }^{[17]}$ it can be expected that a higher strength can be achieved in the Sn-coating aided compound castings.

\section{CONCLUSIONS}

From this research, the following conclusions can be drawn:

(1) The wettability of steel substrate to liquid A356 aluminum alloy is significantly improved by a Sn-coating layer at the steel surface. The improved wettability is ascribed to the breaking-up effect of molten $\mathrm{Sn}$ on the aluminum oxide layers at the aluminum droplet surface.

(2) Successful metallurgical bonding between A356 aluminum alloy and Sn-coated mild steel was achieved through compound casting. A large advantage of Sn-coating is that no preheating of the steel inserts or the casting mold is needed for the casting process, which resulted in a thinner reaction layer, with an average thickness of $12 \mu \mathrm{m}$. In the continuous intermetallic reaction layer, $\beta-\mathrm{Al}_{4}{ }_{5} \mathrm{FeSi}$, $\alpha-\mathrm{Al}_{7.4} \mathrm{Fe}_{2} \mathrm{Si}$, and $\tau_{11}-\mathrm{Al}_{4} \mathrm{Fe}_{1.7} \mathrm{Si}$ form from the cast aluminum to the steel pipe. At the steel surface, there is a thin layer of binary $\eta-\mathrm{Al}_{5} \mathrm{Fe}_{2}$ with a thickness of less than $1 \mu \mathrm{m}$.

(3) During compound casting, the Sn-coating layer is completely melted and mixed with liquid aluminum. After casting, a small fraction of fine Sn-rich particles is found distributing in the reaction layer and along the eutectic $\mathrm{Si}$ particles. The fraction of Sn-rich particles in the compound casting may be significantly reduced by reducing the thickness of the Sn-coating layer at the surface of the steel insert.

\section{ACKNOWLEDGMENTS}

The authors are grateful for the Research Council of Norway for financial support through the IPN project AluLean (project number 90141902), SINTEF Industry for mold production and casting facilities, and Aludyne Norway AS for contribution of materials.

\section{CONFLICT OF INTEREST}

On behalf of all authors, the corresponding author states that there is no conflict of interest.

\section{FUNDING}

Open access funding provided by NTNU Norwegian University of Science and Technology (incl St. Olavs Hospital - Trondheim University Hospital).

\section{OPEN ACCESS}

This article is licensed under a Creative Commons Attribution 4.0 International License, which permits use, sharing, adaptation, distribution and reproduction in any medium or format, as long as you give appropriate credit to the original author(s) and the source, provide a link to the Creative Commons licence, and indicate if changes were made. The images or other third party material in this article are included in the article's Creative Commons licence, unless indicated otherwise in a credit line to the material. If material is not included in the article's Creative Commons licence and your intended use is not permitted by statutory regulation or exceeds the permitted use, you will need to obtain permission directly from the copyright holder. To view a copy of this licence, visit http://creativecommons.org/licenses/by/4.0/.

\section{REFERENCES}

1. A. Bouayad, C. Gerometta, A. Belkebir, and A. Ambari: Mater. Sci. Eng. A, 2003, vol. 363, pp. 53-61.

2. X. Cui, H. Zhang, S. Wang, L. Zhang, and J. Ko: Mater. Des., 2011, vol. 32, pp. 815-21.

3. H. Springer, A. Kostka, E.J. Payton, D. Raabe, A. Kaysser-Pyzalla, and G. Eggeler: Acta Mater., 2011, vol. 59, pp. 1586-1600.

4. Y. Huang, T. Huang, L. Wan, X. Meng, and L. Zhou: J. Mater. Process. Technol., 2019, vol. 263, pp. 129-37.

5. J. Fan, C. Thomy, and F. Vollertsen: Phys. Procedia, 2011, vol. 12, pp. $134-41$.

6. C. Wang, Y. Jiang, J. Xie, D. Zhou, and X. Zhang: Mater. Sci. Eng. A, 2016, vol. 652, pp. 51-58.

7. M. Dehghani, A. Amadeh, and S.A.A. Akbari Mousavi: Mater. Des., 2013, vol. 49, pp. 433-41.

8. K.J.M. Papis, J.F. Loeffler, and P.J. Uggowitzer: Sci. China Technol. Sci., 2009, vol. 52, pp. 46-51.

9. G.R. Zare, M. Divandari, and H. Arabi: Mater. Sci. Technol., 2013, vol. 29, pp. 190-96.

10. A.M. Tavakoli, B. Nami, M. Malekan, and I. Khoubrou: Int. J. Metalcast., 2021.

11. M. Sistaninia, H. Doostmohammadi, and R. Raiszadeh: Metall. Mater. Trans. B, 2019, vol. 50B, pp. 3020-26.

12. H. Springer, A. Szczepaniak, and D. Raabe: Acta Mater., 2015, vol. 96, pp. 203-11.

13. O. Dezellus and N. Eustathopoulos: J. Mater. Sci., 2010, vol. 45, pp. 4256-64

14. M.M. Abd Elnabi, T.A. Osman, A. El Mokadem, and A.B. Elshalakany: J. Mater. Res. Technol., 2020, vol. 9, pp. 10209-22.

15. G. Aylward and T. Findlay: SI Chemical Data, 5th ed., John Wiley \& Sons Australia, Milton, 2002.

16. W. Jiang, G. Li, Y. Wu, X. Liu, and Z. Fan: J. Mater. Process. Technol., 2018, vol. 258, pp. 239-50.

17. S. Seifeddine, S. Johansson, and I.L. Svensson: Mater. Sci. Eng. A, 2008, vol. 490, pp. 385-90.

18. J. Shin, T. Kim, K. Lim, H. Cho, D. Yang, C. Jeong, and S. Yi: $J$. Alloys Compd., 2019, vol. 778, pp. 170-85.

19. A.O. Bakke, L. Arnberg, J.O. Løland, S. Jørgensen, J. Kvinge, and Y. Li: J. Alloy. Compd., 2020, vol. 849, p. 156685.

20. T. Tanaka, M. Nezu, S. Uchida, and T. Hirata: J. Mater. Sci., 2020, vol. 55, pp. 3064-72.

21. T.B. Massalski, H. Okamoto, P.R. Subramanian, and L. Kacprzak: Binary Alloy Phase Diagrams: 1: Ac-Ag to Ca-Zn in Binary Alloy Phase Diagrams, 2nd ed., ASM International, Materials Park, 1990, vol. 2.

22. A.M. Sarkis, A. Robin, V.A. Souza, and P.A. Suzuki: Mater. Charact., 2011, vol. 62, pp. 621-25.

23. Lager katalog- Smith Stål, 2013, https://magasin.byggern.no/staal/ lagerkatalog/. Accessed 10 Aug 2020. 
24. J. Yang, S. Bao, S. Akhtar, P. Shen, and Y. Li: Metall. Mater. Trans. B, 2021, vol. 52B, pp. 382-92.

25. K. Bouché, F. Barbier, and A. Coulet: Mater. Sci. Eng. A, 1998 , vol. 249 , pp. 167-75.

26. J.C. Viala, M. Peronnet, F. Barbeau, F. Bosselet, and J. Bouix: Compos. Part A: Appl. Sci. Manufact., 2002, vol. 33, pp. 1417-20.

27. S. Bao, K. Tang, A. Kvithyld, M. Tangstad, and T.A. Engh: Metall. Mater. Trans. B, 2011, vol. 42B, pp. 1358-66.

28. Q. Lin, W. Zhong, F. Li, and W. Yu: J. Alloy. Compd., 2017, vol. 716, pp. 73-80.

29. X. Liu, M.Q. Zeng, Y. Ma, and M. Zhu: Wear, 2008, vol. 265, pp. 1857-63.
30. W. Jiang, Z. Fan, G. Li, and C. Li: J. Alloy. Compd., 2016, vol. 678, pp. 249-57.

31. Z. Ding, Q. Hu, W. Lu, X. Ge, S. Cao, S. Sun, T. Yang, M. Xia, and J. Li: Mater. Charact., 2018, vol. 136, pp. 157-64.

32. J.L. Song, S.B. Lin, C.L. Yang, and C.L. Fan: J. Alloys Compd., 2009, vol. 488, pp. 217-22.

33. M. Pouranvari and M. Abbasi: J. Alloys Compd., 2018, vol. 749, pp. 121-27.

Publisher's Note Springer Nature remains neutral with regard to jurisdictional claims in published maps and institutional affiliations. 